\title{
Traditional vs Internet vs Mobile: Which is More Effective Way to Reach Potential Customers
}

\author{
Chiang-Nan Chao ${ }^{1}$ \\ ${ }^{1}$ Tobin College of Business, St. John's University, Jamaica, New York, USA \\ Correspondence: Chiang-Nan Chao, Tobin College of Business, St. John's University, Jamaica, New York, USA \\ Received: May 7, 2018 \\ Accepted: May 15, 2018 \\ Online Published: May 30, 2018 \\ doi:10.5430/jbar.v7n2p1 \\ URL: https://doi.org/10.5430/jbar.v7n2p1
}

\begin{abstract}
Smartphones have provided their users many niches, particularly for mobile commerce, known as mcommerce. As smartphone penetration around the globe, it has rapidly altered the phone users and the market places, as US mobile devices have penetrated more than $80 \%$ of the population in 2017 . The average adult daily usage of mobile devices outpaced personal computers for the first time, and the users have conducted more commerce activities on their mobile devices than on their personal computers. As a result, predicted by eMarketer, US mcommerce will be a half of the total ecommerce by 2022. The marketers realize that they can better find their customers on the move, and enable them to better target these customers for their products. This research, through an empirical survey, focuses on the smartphone user behavior. The research results provide some useful insights for marketers in their future marketing endeavors.
\end{abstract}

Keywords: digital advertising, internet marketing, traditional media advertising, online advertising, mobile advertising

\section{Introduction}

US retail mcommerce sales increased about $23 \%$ in 2017 to $\$ 151$ billion. That translates to $35 \%$ of retail ecommerce sales and $3 \%$ of total retail sales for the year. The bulk of US retail mcommerce growth is in line with the rapid growth of smartphone sales, as US smart phone has penetrated nearly $80 \%$ of the population in 2017 , and the average adult daily usage of smart phone had outpaced the uses of personal computers for the first time a year earlier (eMarketer, 2017; Statista, 2017).

Fourth-generation (4G) traffic exceeded third-generation (3G) traffic for the first time in 2015. In 2017, the 4G connection penetrated $87 \%$ of the US population (Wikipedia, online), while the mobile traffic accounted for about $9 \%$ of the total traffic. Mobile offload has exceeded cellular traffic for the first time since 2015. Fifty-one percent of Total mobile data traffic accounted for $51 \%$ on the fixed network through Wi-Fi or mobile network in 2015 . In total, 3.9 exabytes of mobile data traffic were offloaded monthly onto the fixed network (Cisco, 2017).

The phenomenon of rapid growing smartphones and mobile traffic become interesting for the researchers to explore the smartphone user behavior, and this empirical study intends to focus on the smartphone user pattern, in order to learn some insights for marketer in their strategic thinking.

\section{Review of Literature}

The global market for smartphones has increased rapidly in the past years that make it easier for the users to browse on the web for a variety of products. Figure 1 presents the global smartphone shipment in the past years. 


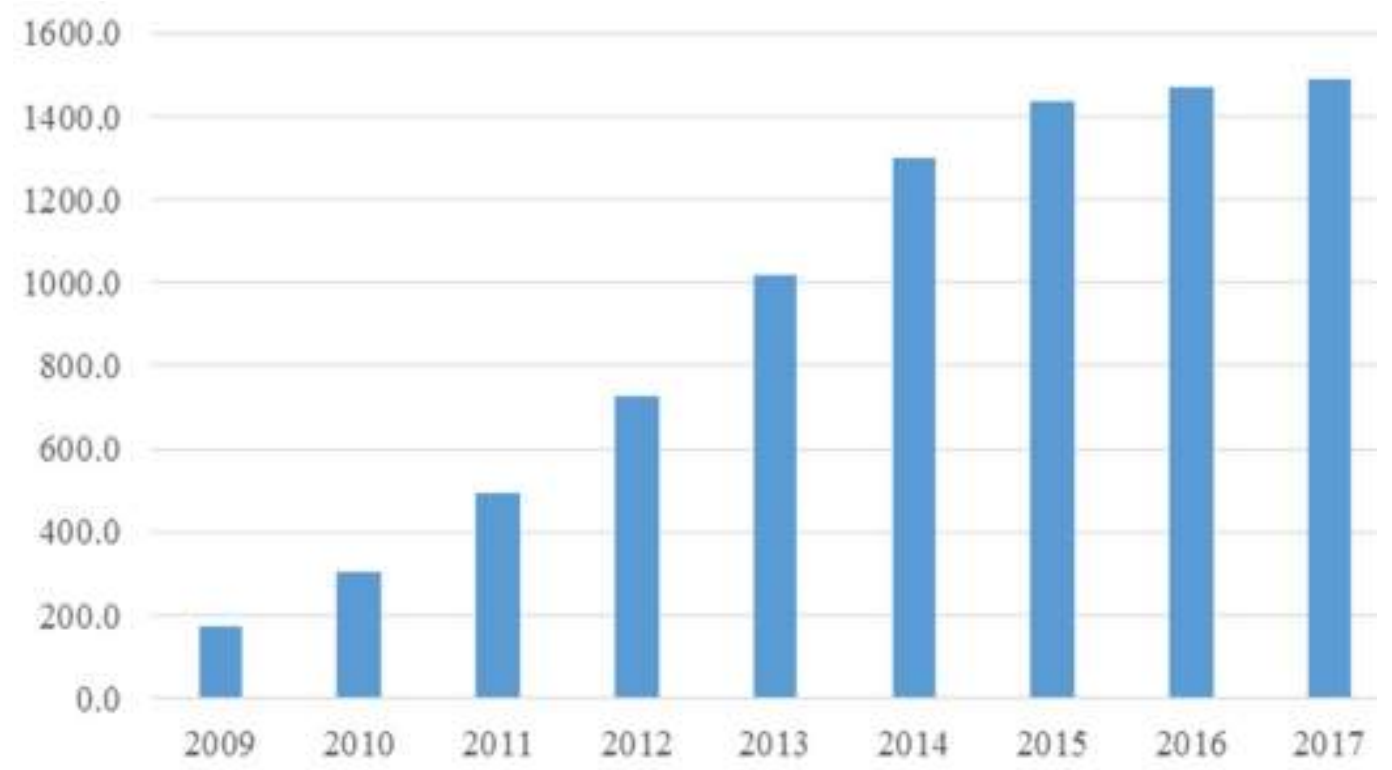

Figure 1. Global smartphone shipment, 2009-2017, in mil of units.

Source: Statista, 2017. https://www.statista.com/statistics/263441/global-smartphone-shipments-forecast/

During the past seven years, adults have spent more time on their smartphones, than on their computers and the traditional media. Figure 2 illustrates the changes.

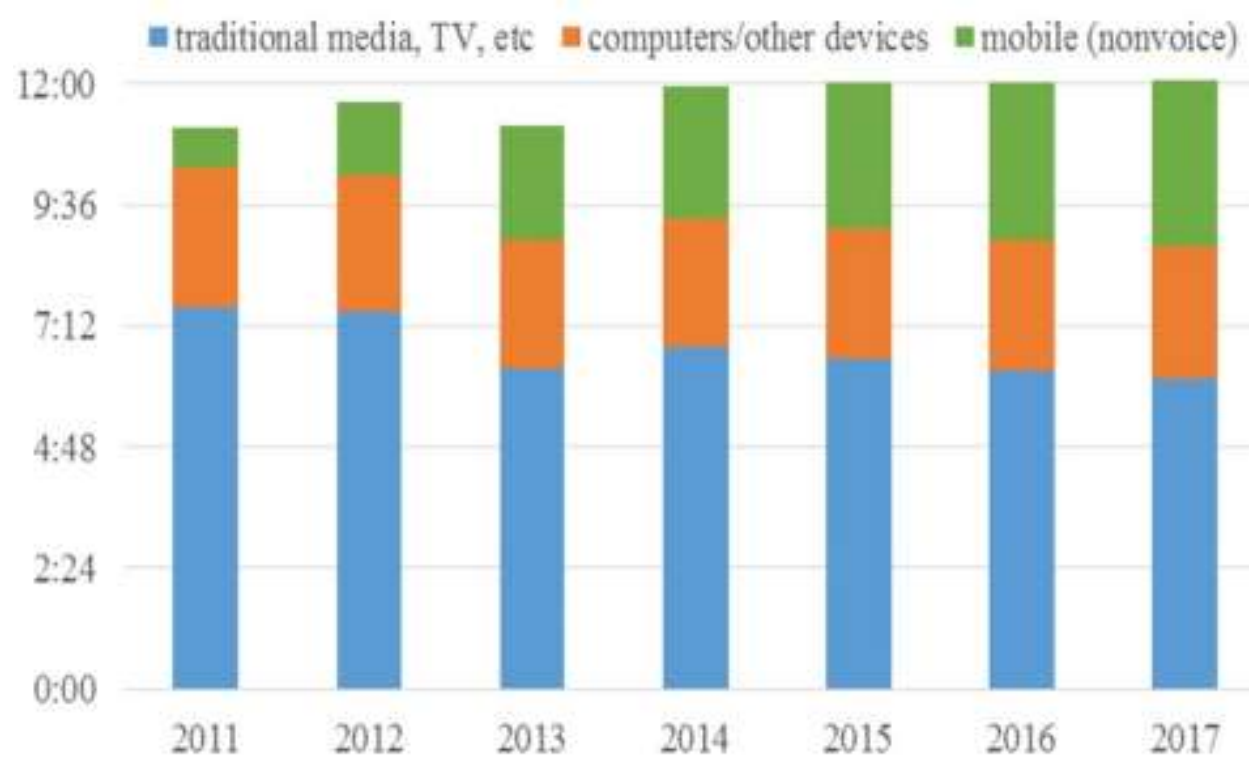

Figure 2. Time spent per adult user per day on different media, USA

Source: http://www.smartinsights.com/mobile-marketing/mobile-marketing-analytics/mobile-marketing-statistics/

Fulgoni and Lipsman (2016) studied future mobile commerce. They discovered that marketers who looked only at the bottom-line effects of mobile shopper activities on retailing were missing important clues about the future. "Mobile still is not a significant channel in driving actual purchases," observe comScore, Inc. CEO, Gian M. Fulgoni, and VP of Marketing and Insights, Andrew Lipsman. Yet, "data from Deloitte forecast that in 2016, mobile will have influenced $\$ 689$ billion in U.S. in-store sales, up from just \$158 billion in 2012-a compound annual growth rate of 45 percent. These mobile-influenced sales figures account for in-store product purchases for which a mobile device aided in the shopping experience". Figure 3 presents the advertising spending on mobile phone as compared to such spending on all media. 


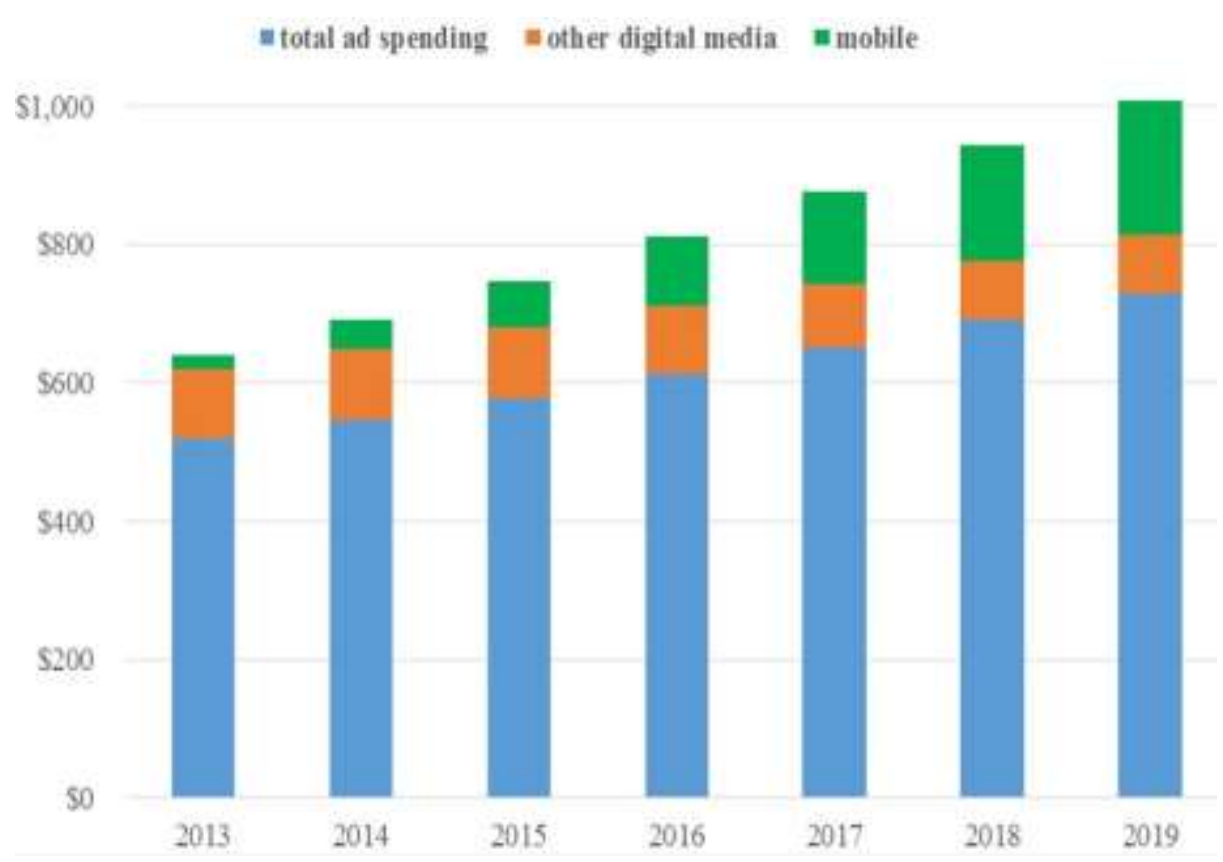

Figure 3. Global mobile Ad spending, in bil. of US\$

Source:

https://www.emarketer.com/Article/Mobile-Ad-Spend-Top-100-Billion-Worldwide-2016-51-of-Digital-Market/1012 299

According to a survey conducted by Clutch, a B2B research firm, almost seven in 10 mcommerce app users in the US access the apps to receive deals and offers. Nearly as many said they appreciate them for the flexibility to buy at any time. New data from The Integer Group illustrates the rapid shift of consumer behavior over the past few years. The percentage of internet users who made purchases via mobile device rose substantially, from just a quarter in 2012 to nearly two-thirds in 2016 (eMarketer, 2017).

Yang and Lee (2017) focused on distinguishing mobile interactivity (m-interactivity) from interactivity via fixed broadband Internet (e-interactivity). The authors, through their exploratory factor analysis and confirmatory factor analysis, studied several comprehensive dimensions of interactivity, and identify four key dimensions of mobile interactivity. They founded the impact of m-interactivity on the consumer response variables of enjoyment, satisfaction, and loyalty, as well as the relationships among them.

Stewart and Cunningham (2017), and Ford (2017) studied the mobile form of marketing and revealed that this platform offered consumers unique experiences and a diverse selection of content. They discovered that with so many platforms at consumers' disposal, advertisers struggle to track the usage of each platform and the response to advertising on it. They believed that marketers wanted to reach, resonate with, and evoke a reaction from the right customers at the right time, which increases the importance of multiplatform metrics. They provided further theoretical explanations and managerial implications.

Hsu and Yeh (2018) find four critical success factors that influence M-commerce adoption: perceived ease of use, perceived usefulness, value-added and service functionality. In addition, these factors were identified as the cause and effect factors. The results of this study are presented to M-commerce service providers' in facilitating the development of wireless services. Lin, et al (2017) explored the determinants of consumers' use of mobile commerce, and their act of payment. They found that security concerns and privacy concerns are the most important factors.

Raphaeli, et al (2017) analyzed online consumer behavior in mobile and PC devices. They investigated and compared online consumer behavior on an e-retailer website in mobile versus PC devices, through the application of a web usage mining approach on clickstream data recorded in server-side log files. Online shopper behavior is described through both engagement measures and the discovery of common sequences of navigation patterns, using an innovative approach that combines footstep graph visualization with sequential association rule mining. They found that sessions conducted through mobile devices are more likely to consist of task-oriented behavior whereas sessions conducted 
through PC devices are characterized by a more exploration-oriented browsing behavior. They also found that certain sequence rule were associated with an increased likelihood of purchase in both mobile and PC sessions.

Chao (2017) investigated mobile commerce, which has emerged as an important sector in retail businesses, as US smartphones have penetrated near $80 \%$ of the population in 2017 . The average adult daily usage of smart phone outpaced personal computers for the first time, and the users do more commerce on their smartphones than on their personal computers. As predicted by eMarketer US mcommerce will be a half of the total ecommerce by 2020 . As a result, marketers have spent advertisement on smartphones. The marketers realize that they can better target smartphone users through programmatic advertising, particularly when they find the phone users are interested in particular products they browse. This research, through an empirical survey, focuses on the effectiveness of mobile marketing. The research results confirm this marketing trend, and provide some useful insights for marketers in their future marketing endeavors.

The review of literature tenders a wide range of aspects of mobile commerce. While this study intends to focus only on the fundamental issues: the limited aspects of smartphone user behavior, and comparisons of computer and smartphone usages. The objective of the study intends to provide some insights to marketers that would help them better reach their customers.

\section{Methodology}

This study focuses on the advertising effectiveness on smartphone users. A survey questionnaire was designed to investigate the features that were most important for the advertisers.

\subsection{Variable Selection}

The variables that were selected are based on our literature review. Twelve research variables were identified from the review of literature and presented below. The respondents were asked to identify how frequently they were aware of the advertising messages, presented either in the mobile form or in the form of the traditional media. The respondents were asked to evaluate the frequency they would notice each of these variable messages advertised in mobile advertising and in traditional media advertising. Five point Likert scale is applied, with $5=$ always, $4=$ mostly, $3=$ frequently, $2=$ occasionally, $1=$ never.

The following variables were evaluated:
1). Product quality and features offering
2). Offering free samples
3). Offering free trials
4). Offering attractive prices
5). Offering discounts and promotion
6). Offering coupons
7). Offering rebates
8). Offering incentives to buyers in an online store or retail stores
9). Offering free delivery or delivery incentives
10). Offering prizes
11). Offering sweepstakes
12). Offering sport or cultural sponsorship

\subsection{Sampling, Hypotheses, and Tests of Hypotheses}

The targeted sample respondents were college students at a large university in the northeast of the U.S. One-page survey questionnaires were distributed online over the past semesters to target respondents, specifically with the aim of obtaining the opinions of the respondents who are often exposed to both traditional and mobile advertising. The null hypotheses for this study stated:

Hypothesis 1. There is no significant difference in product quality and/or features offering among mobile, computer, and traditional media advertising.

Hypothesis 2. There is no significant difference in offering free samples among mobile, computer, and traditional media advertising. 
Hypothesis 3. There is no significant difference in offering free trials among mobile, computer, and traditional media advertising.

Hypothesis 4. There is no significant difference in offering attractive prices among mobile, computer, and traditional media advertising.

Hypothesis 5. There is no significant difference in offering discounts and promotion among mobile, computer, and traditional media advertising.

Hypothesis 6. There is no significant difference in offering coupons among mobile, computer, and traditional media advertising.

Hypothesis 7. There is no significant difference in offering rebates among mobile, computer, and traditional media advertising.

Hypothesis 8. There is no significant difference in offering incentives to buyers in the mobile media store or retail stores among mobile, computer, and traditional media advertising.

Hypothesis 9. There is no significant difference in offering free delivery or delivery incentives among mobile, computer, and traditional media advertising.

Hypothesis 10. There is no significant difference in offering prizes among mobile, computer, and traditional media advertising.

Hypothesis 11. There is no significant difference in offering sweepstakes among mobile, computer, and traditional media advertising.

Hypothesis 12. There is no significant difference in offering sport or cultural sponsorship among mobile, computer, and traditional media advertising.

The alternative hypotheses state: there is a significant relationship between the respondents' views of mobile, computer, and traditional media advertising over these selected variables.

The One-Way ANOVA ("analysis of variance") compares the means of two or more independent groups in order to determine whether there is statistical evidence that the associated population means are significantly different. One-way ANOVA is a parametric test.

It is important to realize that the one-way ANOVA is an omnibus test statistic and cannot tell you which specific groups were statistically significantly different from each other; it only tells you that at least two groups were different. Since you may have three, four, five or more groups in your study design, determining which of these groups differ from each other is important. You can do this using a post hoc test (N.B., we discuss post hoc tests later in this guide).

The test statistic for a One-Way ANOVA is denoted as F. For an independent variable with $\mathrm{k}$ groups, the F statistic evaluates whether the group means are significantly different.

The null hypotheses should be rejected if the significance level is less than or equal to 5\% in any one criterion (Hamburg, 1977; Conover, 1980; Davis and Cosenza, 1985; IBM SPSS Exact Tests, SPSS Inc. 2010).

\section{Results}

One thousand five hundred questionnaires were distributed college students and staffs in a large university in the northeast of the U.S., of which three hundred ninety three were returned and usable. This represents roughly 26.2 percent response rate. The following table presents the background information of these respondents, including gender and income. 
Table 1. Background Information of the Respondents

\begin{tabular}{cl}
\hline Age & Valid \% \\
$<18$ & 1.2 \\
$18-35$ & 94.9 \\
$35-50$ & 3.4 \\
$>50$ & 0.5 \\
Gender & \\
Male & 53.2 \\
Female & 46.8 \\
Income & \\
$<$ \$35k & 16.2 \\
\$35-50k & 21.8 \\
\$50-70k & 21.5 \\
$>$ \$70k & 40.5 \\
Education & \\
College & 91.9 \\
Graduate & 8.1 \\
Marital status & \\
Married & 23.2 \\
Single & 76.8 \\
\hline Source: original &
\end{tabular}

Table 2. ANOVA test results

\begin{tabular}{lll}
\hline Variables & $\boldsymbol{F}$ & Sig. \\
\hline Product quality and features offering & $\mathbf{4 3 . 4 9 9}$ & $\mathbf{0 . 0 0 0}$ \\
Offering free samples & $\mathbf{2 7 . 0 2 1}$ & $\mathbf{0 . 0 0 0}$ \\
Offering free trials & $\mathbf{1 2 . 3 6 7}$ & $\mathbf{0 . 0 0 0}$ \\
Offering attractive prices & $\mathbf{2 2 . 7 5 5}$ & $\mathbf{0 . 0 0 0}$ \\
Offering discounts and promotion & $\mathbf{2 3 . 9 1 5}$ & $\mathbf{0 . 0 0 0}$ \\
Offering coupons & $\mathbf{2 0 . 0 9 3}$ & $\mathbf{0 . 0 0 0}$ \\
Offering rebates & $\mathbf{4 0 . 7 3 5}$ & $\mathbf{0 . 0 0 0}$ \\
Offering incentives to buyers in online store or retail stores & $\mathbf{1 1 4 . 6 6 5}$ & $\mathbf{0 . 0 0 0}$ \\
Offering free delivery or delivery incentives & $\mathbf{3 . 7 7 6}$ & $\mathbf{0 . 0 2 3}$ \\
Offering prizes & 0.007 & 0.993 \\
Offering sweepstakes & 0.034 & 0.967 \\
Offering sport or cultural sponsorship & 1.177 & 0.309 \\
\hline Source: original & &
\end{tabular}

ANOVA Test results show that nine variables out of total twelve variables have significant levels less than 5\% (highlighted in bold). Therefore, the corresponding hypotheses are rejected. Three variables with significant levels of greater than $5 \%$, so the corresponding hypotheses are accepted. 


\section{Conclusions}

ANOVA Test results conclude that there are statistically significant differences from the consumers' viewpoints among smartphone, computer, and traditional media advertising. The findings suggest that traditional media will continue to hold its position as a result of the rise of the smartphone and computer. The three may work more effectively together to yield better advertising.

The rejections of Product quality and features offering, Offering free samples, Offering free trials, Offering attractive prices, Offering discounts and promotion, Offering coupons, Offering rebates, Offering incentives to buyers in online store or retail stores, Offering free delivery or delivery incentives, indicate the respondents still favor different media advertising, even the respondents spend more time on their smartphones and computers, and explore the offers of various products and/or services on their smartphones and computers, and it seems much easier for the users to access these offers. The rejections offer a glimpse that more promotion can be better targeted the potential buyer groups via smartphones, rather than in the traditional media.

This study accepts three hypotheses: Offering prizes, Offering sweepstakes, Offering sport or cultural sponsorship, as there are no statistically significant differences in effectiveness of the listed marketing activities among smartphone, computer, and traditional media advertising. This may suggest, from the consumers' viewpoints, it is less important for advertisers focusing on these issues when they are allocating funds to different advertising media.

The findings of this study may also suggest that traditional media advertising is still an effective way to send the messages to the target customers as compared to the smartphone advertising messages. The credibility of this suggestion should be tested further, as this study has a preliminary nature. Smartphone and computer advertising has emerged as a great challenge to traditional media advertising, not only because of its many advantages, but also because it gives advertisers an additional channel to reach their potential customers and often obtain instant feedback.

While researchers are inquiring the truth, practitioners are experimenting with new ways to reach their target customers; therefore the crowded advertising market is getting more crowded. The results of this research also suggest that smartphone advertising has a strong presence, and it will work hand-in-hand with traditional media advertising. Traditional media advertising still carries more weights, as it still attract more advertising dollars. An important value of balanced strategies with different focuses among smartphone, computer, and traditional media advertising in conjunction with the age groups will make advertising industry more effective.

\section{Limitations and Future Research}

The academic research that focuses on comparisons among smartphone, computer, and traditional media advertising is limited, and it may take some years before significant research publications are available. As a preliminary and exploratory research, this study has provided if only limited glimpses of some fundamental aspects of a smartphone, computer, and traditional media advertising.

Further in-depth research should delve more into the factors and elements that predict the effectiveness of traditional media versus all digital (both smartphone and computer) advertising. Would consumers eventually prefer more digital advertising in the future? Does the younger generation differ from the older generation since younger people work more smartphone? As some of the respondents commented, they find using the smartphone enable them to handily obtain products and/or service related information. These issues should also be addressed in future research.

\section{References}

Chao, C. (2017). Emergence Impacts of Mobile Commerce: An Exploratory Study, Journal of Management and Strategy, 8(2), 63-70. https://doi.org/10.5430/jms.v8n2p63

Cisco, (2017). Virtual Network Index Report. Retrieve at: http://www.cisco.com/c/en/us/solutions/collateral/service-provider/visual-networking-index-vni/mobile-white-p aper-c11-520862.html

Conover, W. J. (1980). Practical Nonparametric Statistics, 2nd ed., New York: John Wiley \& Sons, 213-337 \& 344-384.

Davis, D., \& Cosenza R. M. (1985). Business Research for Decision Making. Boston: Kent Publishing.

eMarketer

(2017). Source: http://www.emarketer.com/Article/Mobile-Account-More-than-Half-of-Digital-Ad-Spending-2015/1012930

Ford, J. B. (2017). What Do We Know about Mobile Media and Marketing? Journal of Advertising Research, 57(3), 1 September 2017. https://doi.org/10.2501/JAR-2017-032 
Fulgoni, G. M. \& Lipsman, A. (2016). The Future of Retail Is Mobile, Journal of Advertising Research, June, 56(4), 346-351. https://doi.org/10.2501/JAR-2016-041

Hamburg, M. (1977). Statistical Analysis for Decision Making. San Diego: Harcourt.

IBM SPSS Exact Tests, SPSS Inc. 2010.

Hsu, C. W., \& Yeh, C. C. (2018). Understanding the critical factors for successful M-commerce adoption, International Journal of Mobile Communications, 16(1), 50 - 62. https://doi.org/10.1504/IJMC.2018.088272

Lin, W. R., Wang, Y. H. \& Shih, K. H. (2017). Understanding consumer adoption of mobile commerce and payment behavior: an empirical analysis. International Journal of Mobile Communications, 15(6), 628 - 654. https://doi.org/10.1504/IJMC.2017.10005646

Raphaeli, O., Goldstein, A., and Fink, L. (2017). Analyzing online consumer behavior in mobile and PC devices: A novel web usage mining approach, Electronic Commerce Research and Applications, 26, November-December, 1-12. https://doi.org/10.1016/j.elerap.2017.09.003

Statista. (2017). https://www.statista.com/statistics/263441/global-smartphone-shipments-forecast/

Stewart, K \& Cunningham, I. (2017). Examining Consumers' Multiplatform Usage And Its Contribution to Their Trust in Advertising--The Impact of the Device on Platform-Use Frequency And Trust in Advertising across Platforms. Journal of Advertising Research, 57(3), 1 September 2017. https://doi.org/10.2501/JAR-2017-003

Yang, S. \& Lee, Y. J. (2017). The Dimensions of M-Interactivity and Their Impacts in the Mobile Commerce Contex. International Journal of Electronic Commerce, 21(4), 548-571. https://doi.org/10.1080/10864415.2016.1355645 